\title{
O PROCESSO DE ESTÁGIO NA FORMAÇÃO DOCENTE DE PROFESSORES DE LÍNGUA INGLESA: UM OLHAR DE LICENCIANDAS DE UM CURSO DE LETRAS
}

\author{
EL PROCESO DE ESTADIO EN LA FORMACIÓN DOCENTE DE PROFESORES \\ DE LENGUA INGLESA: UNA MIRADA DE LICENCIANDAS DE UN CURSO DE \\ LETRAS
}

\section{THE INTERNSHIP PROCESS IN THE TEACHER EDUCATION OF ENGLISH LANGUAGE TEACHERS: THE PERSPECTIVE OF A LETRAS COURSE UNDERGRADUATE STUDENTS}

\author{
Caique Fernando da Silva FISTAROL ${ }^{1}$ \\ Adriana FISCHER ${ }^{2}$ \\ Cyntia BAILER ${ }^{3}$
}

RESUMO: Este estudo vislumbrou compreender de que forma três licenciandas de um curso de Letras Português/Inglês compreendiam as práticas de letramentos em inglês no contexto universitário. Para tanto, a metodologia adotada foi de cunho qualitativo, e utilizou de quatro instrumentos de investigação: questionário semiaberto; entrevista narrativa; relatórios de estágio; e, produção de relatos pessoais. Para a análise dos dados, estes foram divididos em três eixos: práticas de letramentos em inglês antes do curso, durante o curso universitário e práticas de letramentos para a formação docente. Assim, os dados das análises indicam que a construção dos discursos sobre a língua inglesa interfere na formação das identidades dos sujeitos deste estudo, apontando que a escola fundamentou as atividades formais, informais e de lazer com o inglês, marcando a pedagogização dos letramentos.

PALAVRAS-CHAVE: Letramentos acadêmicos. Práticas em inglês. Curso de Letras. Estágio. Identidade docente.

RESUMEN: Este estudio previsto entender cómo tres licenciandas de un curso de Letras Portugués/Inglés se dieron cuenta de las prácticas de letramento en Inglés en el contexto universitario. Para eso, la metodología adoptada fue de cuño cualitativo, que se utilizó de cuatro instrumentos de investigación: cuestionario semiabierto; entrevista narrativa; informes de prácticas; y la producción de relatos personales. Para el análisis de los datos,

${ }^{1}$ Universidade Regional de Blumenau (FURB), Blumenau - SC - Brasil. Mestre em Educação pela linha de Linguagens, Arte e Educação, do Programa de Pós-Graduação em Educação (PPGE). E-mail: cfersf@gmail.com.

${ }^{2}$ Universidade Regional de Blumenau (FURB), Blumenau - SC - Brasil. Docente no departamento de Letras da FURB e no PPGE Doutora em Linguística pelo Programa de Pós-Graduação em Linguística da Universidade Federal de Santa Catarina. E-mail: fischer.furb@gmail.com.

${ }^{3}$ Universidade Regional de Blumenau (FURB), Blumenau - SC - Brasil. Docente no departamento de Letras da FURB, e colaboradora no PPGE.Doutora em Estudos da Linguagem pelo Programa de Pós-Graduação em Inglês da Universidade Federal de Santa Catarina. E-mail: cbailer@ furb.br. 
estos fueron divididos en tres ejes: prácticas de letramentos en inglés antes y durante el curso universitario; y prácticas de letramentos para la formación docente. Así, a partir de los análisis se concluyó que la construcción de los discursos sobre la lengua inglesa interfiere en la formación de las identidades de los sujetos, indicando que la escuela fundamentó las actividades formales, informales y de ocio con el inglés, marcando la pedagogización de los letramentos.

PALABRAS-CLAVE: Letramentos académicos. Prácticas en Inglés. Curso de Letras. Etapa docente. Identidad docente.

ABSTRACT: This study sought to comprehend how three undergraduates of a Portuguese/English Languages and Literatures course for teaching perceived the literacy practices in English in the university context. For that, the qualitative methodology was adopted, with four instruments: semi-open questionnaire; narrative interview; internship reports; and, the production of memoir texts. For the analysis, the data were divided into three axes: literacy practices in English before and during the undergraduation course; and, literacy practices for teacher education. Thus, the analyses reveal that the construction of discourses about the English language interferes in the development of the subjects' identities, indicating that the school context substantiated the formal, informal, and leisure activities with English, marking the pedagogization of literacies.

KEYWORDS: Academic Literacies. Practices in English. Letras course. Internship. Teacher identity.

\section{Introdução}

Ao iniciar o presente estudo, inserido na linha de pesquisa Linguagens e Letramentos na Educação, muitos eram os questionamentos acerca do processo de formação docente por meio dos estágios do curso de licenciatura, isto é, de que forma a teoria e a prática de estágio seriam suficientes para a transformação de um acadêmico do curso de Letras Português/Inglês em um professor em formação e posterior docente da língua inglesa. A partir destas e tantas outras reflexões, a inquietação por respostas possibilitou a estruturação e proposição de um projeto de mestrado em Educação, que se tornou dissertação, cujo objetivo geral era compreender sentidos construídos sobre práticas de letramentos em inglês por licenciandas de um curso de Letras Português/Inglês no contexto universitário para a formação docente. Dados foram gerados em busca de resposta a essas inquietações, os objetivos deste artigo são compreender trajetórias de licenciandas com a língua inglesa em experiências anteriores ao ingresso na universidade; analisar práticas de letramentos em/com inglês durante a formação acadêmica, e compreender 
como se desenvolveu a formação profissional desses sujeitos a partir de práticas vivenciados na universidade.

Parte-se do pressuposto de que um docente que sabe ensinar a língua desejada possa incentivar seus alunos a desenvolveram autonomia para buscar por novos conhecimentos. Acredita-se que esse processo só será tangível se o docente estiver inserido em práticas diversas de letramentos (STREET, 2014). Nessa direção, Dionísio (2007) destaca a importância de promover em sala de aula reflexões sobre as atividades desenvolvidas, buscando construir um pensamento analítico, classificatório e crítico.

Nesse contexto, Leffa (2008) aborda a questão comparando o ensinar uma língua como uma ação política, em que o suporte informacional por meio do qual se ensina os estudantes, está imbuído de ideologias (sociais e/ou políticas), orientações revolucionárias, preconceitos, movimentos de luta, dentre outros.

Evidentemente, que os textos permitem ao estudante apoderar-se das ideias e refletir o que dentro daquele contexto pode ser assimilado na construção de sua identidade crítica como uma pessoa que vive em sociedade, porque é a partir da sua interação com o meio, com os demais cidadãos, que se forma um sujeito (BAKHTIN, 2003).

Neste caminho, as práticas de letramentos ocorridas, nas instituições de ensino superior, poderiam oportunizar minimamente competências (linguísticas e pedagógicas) necessárias, com a finalidade de qualificar e conduzir os docentes em formação para que estes trilhassem pelo social, dialógico e crítico, conforme expõem Lea e Street (2006).

Embora a prática fuja um pouco do que é apreendido na academia, Ghiraldelo (2006, p. 15) salienta uma realidade entristecedora sobre o ensino brasileiro, quando aborda que "[...] boa parte dos alunos [...] não escrevem, nem leem com a proficiência esperada - ou desejada pelo corpo docente - para um aluno de curso de nível superior". Diante de tal constatação, Vóvio (2012, p. 4) lembra que desde os princípios educacionais de Paulo Freire, o país deveria "[...] considerar a realidade social tanto dos sujeitos como dos contextos em que essas ações serão desenvolvidas [...]. No entanto, a concretização dessa máxima em programas e práticas pedagógicas [...] apresenta-se ainda como um grande problema a ser superado".

Com isso, uma nova reflexão é proposta: será que as universidades não estão considerando a realidade e contexto social dos sujeitos diante da sua formação e necessidade de exercer a prática docente? Embora seja uma pergunta complexa e que envolva muitos fatores, o foco aqui, sob o qual se tem a lupa, refere-se à aprendizagem da 
língua inglesa, em que o sujeito precisa se constituir e se desenvolver como um acadêmico, profissional e pessoa, mas que ante sua formação precisa ser orientado e conduzido pelos caminhos do ensino-aprendizagem para apropriar-se de conhecimentos que o constituirão.

Para que haja esta apropriação, Ferreira e Santos (2010) sugerem que compete ao educador dominar e utilizar das diversas ferramentas de ensino para auxiliar no decorrer do processo de ensino-aprendizagem do acadêmico em formação. De tal modo, é imprescindível que os letramentos acadêmicos alcancem o seu propósito, o de preparar o estudante a buscarem o uso de diferentes ferramentas para sua autonomia e formação. Lea e Street (2006, p. 229, tradução nossa) asseveram que os letramentos acadêmicos exigem dos estudantes o "[...] domínio de habilidades de estudo ou a socialização no ambiente acadêmico. Requer atenção especial às relações de poder, autoridade, produção de sentidos e identidade que estão implícitas no uso de práticas de letramento em contextos institucionais específicos".

Portanto, nesta seara, o presente artigo inicia com a introdução, aborda a revisão teórica, que perpassa pelo estágio docente como formação e desenvolvimento profissional, a docência em língua inglesa como processo formativo, a partir da concepção de inglês como língua franca e, os letramentos em língua inglesa, do estágio à práxis. Em seguida, faz-se uma breve descrição da metodologia adotada, apresentam-se a análise dos dados e as considerações finais.

\section{Estágio docente: formação e desenvolvimento profissional}

Durante o estágio docente, a formação e o desenvolvimento profissional podem ser processos individuais ou coletivos. Conforme Marcelo (2009, p. 10), esta formação “[...] deve [contribuir] para o desenvolvimento das suas competências profissionais através de experiências de diferente índole, tanto formais como informais". Ou seja, a formação e desenvolvimento do docente será possível quando este desenvolver habilidades profissionais por meio de suas vivências e experiências durante a interação com estudantes e, é neste momento que o estágio agrega em sua formação.

O estágio docente é o momento que o acadêmico e futuro docente está exposto às mais diversas situações e incertezas da profissão. É em campo que ele perceberá e vivenciará momentos de aprendizado durante sua atuação, mas que terá que administrar os desafios diários desta escolha. 
A academia ensina a teoria para fundamentar suas ações, mas é na interação com os estudantes que o acadêmico/docente participará ativamente com outras pessoas, que não são iguais, não pensam e não agem da mesma forma. Neste vasto campo do ensino e aprendizagem, o futuro profissional vivencia experiências que conduzem à sua trajetória profissional.

Marcelo (2009) afirma que as experiências em docência são frutos das interações entre a identidade pessoal e profissional, que, por estarem em constante metamorfose vão se formando sem muita reflexão, como aprendizagem informal, olhando para os modelos docentes com os quais a identidade pessoal e profissional vai se identificando ou não, mas, que essa construção identitária recebe mais influências emocionais do que racionais. A identidade profissional é a forma como os professores definem a si mesmos e aos outros. Essa forma de se ver e de ver o outro sofre influências da escola, dos contextos políticos, do compromisso pessoal e da disposição para aprender a ensinar, e está relacionado às crenças, valores, ao conhecimento sobre a matéria que o professor leciona, com as experiências passadas, e com a vulnerabilidade profissional. Marcelo (2009, p. 9) complementa que o "[...] desenvolvimento profissional docente pode ser entendido como uma atitude permanente de indagação, de formulação de questões e procura de soluções".

Durante o estágio docente, o profissional deve exercitar sua visão para perceber o que está além das salas de aula. Conforme Pimenta e Lima (2011), a prática docente exige a compreensão de como e por que as decisões são tomadas, de que forma o conhecimento acontece no campo do saber. Também envolve as interpretações dos estudantes no processo de ensino-aprendizagem, a administração da vida escolar destes deve ser baseada na legislação regulatória do estabelecimento de ensino, ou seja, o docente deve ser capaz de ter a visão do todo, para atuar de forma ética, eficiente e eficaz perante a sociedade na qual está inserido.

Evidentemente, que todo esse processo de autoconhecimento, aprendizado e ensino requer tempo, paciência, planejamento e discussão com os pares. Nóvoa (1992) apregoa que o professor necessita nutrir uma convivência com o estudante como mediador entre o conhecimento e a realidade em sala de aula e, tornar este espaço e momento em algo que propiciará autonomia ao estudante por meio da ação didática adotada.

O futuro docente deve entender que a sala de aula é um campo de conhecimento, por meio do qual a troca entre os sujeitos deve ser perpetuada. $\mathrm{O}$ ato de ensinar exige do professor muito mais que o conhecimento do conteúdo a ser ministrado, esse deve ter a 
capacidade de transitar por todas as áreas e proporcionar aos estudantes reflexões sobre assuntos da atualidade, orientá-los a se tornarem pessoas éticas e honestas, críticas e reflexivas sobre o que acontece em seu entorno.

A prática do estágio docente serve para mostrar ao acadêmico que a sua atuação deve transpor o conteúdo, ir além de metodologias tradicionais de ensino. Como bem exemplificam Pimenta e Lima (2011), não é a atividade prática, mas a teórica que instrumentaliza a práxis docente, por ser capaz de transformar a realidade. Ou seja, todo docente necessita da teoria para aprimorar a prática e vice-versa. Logo, o estágio docente deve servir para o acadêmico com um campo de exploração, experimentos e aprendizado, pois é neste momento que ele exercitará seu conhecimento teórico, suas ideias, planejamentos e idealizações para constatar se a sua conduta até o momento é satisfatória para ingressar na docência. As reflexões e críticas, como sugere Marcelo (2009), devem ser constantes neste momento, para que o acadêmico consiga identificar em si o que deve melhorar e quais preconceitos devem ser extintos diante da realidade de atuação em campo.

Assim, salienta-se que a prática do estágio docente é o primeiro palco do espetáculo do futuro docente, ação esta que requer planejamento, comprometimento, dedicação, avaliação constante, críticas e reflexões, estudos e debates com os pares, pois nenhum profissional forma-se exclusivamente em sua individualidade. É preciso compreender que ao se dispor para tal ação, deve-se considerar que a docência não é uma atividade técnica simples, e sim complexa, repleta de facetas.

\section{Docência em língua inglesa: processo formativo a partir da concepção de inglês como língua franca}

Para se abordar a docência em língua inglesa, primeiramente deve-se salientar que esta é considerada como língua franca, pois é "[...] uma língua pela qual os membros de diferentes comunidades de fala podem se comunicar entre si, mas que não é a língua materna de nenhum deles" (SEIDLHOFER, 2001, p. 46, tradução nossa). Isto é, o inglês é reconhecido como uma língua franca, pois permite aos mais variados povos (de línguas e culturas distintas) a comunicação. A língua inglesa, conforme explica Seidlhofer (2001), se tornou uma língua franca porque está atrelada ao desenvolvimento econômico e tecnológico nos países ditos desenvolvidos; e está associada a diferentes intenções de uso por estas comunidades; conferindo-lhe tal status, mesmo sem propriedade, global. Porém,

RIAEE - Revista Ibero-Americana de Estudos em Educação, Araraquara, v. 13, n. 20, p. 623-637, abr./jun., 2018. E-ISSN: $1982-5587$. 
Seidlhofer (2001) sinaliza que ensinar inglês como língua franca e não como língua estrangeira tem suas implicações. Dessa forma, o padrão do falante nativo contrasta com as multiplicidades linguísticas, tanto na forma do ensino baseado na cultura e na correção linguística; quanto na redefinição identitária do docente não nativo e de seus estudantes.

O professor deve propor atividades que tenham a cultura como eixo norteador, que favoreçam a criticidade, a autonomia para aprender inglês, mas também permitir que os estudantes formulem suas próprias conclusões sobre a necessidade em aprender tal língua. Mundialmente o inglês é apontado como um facilitador no crescimento profissional e na busca por melhores posições no mercado de trabalho, também é a língua (estrangeira) mais falada no mundo.

\section{Letramentos em língua inglesa: do estágio à práxis}

Fischer (2007) lembra que o meio acadêmico é significativamente diferenciado do que o estudante vivenciou em seu ensino médio. Assim, a sua produção intelectual (leitura, oralidade e escrita) deve se adequar às formalidades e exigências de cada nível de ensino. Mas, para que o docente consiga mostrar ao estudante a necessidade de introduzir e aperfeiçoar novas práticas de letramentos, é preciso partir das experiências sociais que o estudante já tem. Colaço e Fischer (2015) afirmam que, na licenciatura, os acadêmicos necessitam amadurecer seus conhecimentos, adequar suas atitudes ao meio, instituir valores e atuar por meio deles. Ao longo do processo, os sujeitos formarão suas identidades como professores de língua, por meio da interação com seus docentes e colegas de curso.

Nessa temática, Hamilton (2000) e Barton e Hamilton (2005) indicam que os letramentos e as diferentes práticas letradas com as quais o sujeito mantém contato no meio acadêmico são denominadas práticas de letramentos. Entretanto, quando a escrita admite um papel fundamental, em que a produção/situação do texto é basal, os autores qualificam o acontecimento como eventos de letramentos. Portanto, os letramentos são considerados práticas sociais, porque a prática social dos letramentos é plural, tanto nos assuntos sociocomunicativos da leitura e escrita, quanto em circunstâncias diversificadas (STREET, 2014).

Assim, Street (2012, p. 77) pondera a necessidade de explanar que letramentos são compostos de práticas e eventos. As práticas de letramentos são abrangentes, envolvem uma "concepção cultural mais ampla" das formas de pensar e realizar a leitura e a escrita 
em contextos culturais. Com isso, o entendimento dos eventos deve ser acerca das ocasiões em que a escrita desempenha papel primordial nos processos de interação e interpretação entre os partícipes, compondo ações em que os letramentos podem ser notados, como na composição de um texto. Barton e Hamilton (2005, p. 10, tradução nossa) avalizam que os eventos de letramentos "[...] não são os mesmos em todos os contextos. [...] A noção de que há diferentes letramentos traz vários sentidos".

Já Lea e Street (2006, p. 229, tradução nossa) afiançam que os letramentos acadêmicos exigem dos estudantes mais do que o

[...] domínio de habilidades de estudo ou a socialização no ambiente acadêmico. Requer atenção especial às relações de poder, autoridade, produção de sentidos e identidade que estão implícitas no uso de práticas de letramento em contextos institucionais específicos.

No contexto acadêmico, Lea e Street (2006) apontam que há três abordagens dos letramentos: (1) o modelo das habilidades, que vê os letramentos como um conjunto de habilidades individuais e cognitivas que os estudantes devem aprender e desenvolver para que possam transferi-las para contextos mais amplos da universidade; (2) o modelo da socialização acadêmica, no qual a preocupação está na aculturação dos estudantes em disciplinas ao pressupor que devem assimilar os modos de falar, raciocinar, interpretar e usar as práticas de escrita valorizadas na academia; e (3) o modelo dos letramentos acadêmicos, em que a perspectiva é a de entender os sentidos que os sujeitos presentes na academia atribuem ao que nela acontece em termos de leituras e escritas, considerando questões de identidade, relações ideológicas e de poder. Nesse último modelo, em virtude dessas questões e relações, que caracterizam as práticas, muitas dimensões escondidas (FISCHER, 2015) podem ser polemizadas na relação entre orientações didáticopedagógicas e práticas de letramentos efetivamente encaminhadas pelos estudantes no ensino superior.

Para compreender como a teoria dialoga com a análise e os resultados que buscam responder aos objetivos deste estudo, apresenta-se o caminho metodológico utilizado.

\section{O caminhar metodológico, os sujeitos e os instrumentos de investigação e análise}

Este estudo é de cunho qualitativo, que, segundo Vóvio e Souza (2005) prioriza o aprofundamento de determinado tema, em que se deve considerar a interação e retorno das 
informações dos sujeitos envolvidos, bem como as particularidades, especificidades, ações, conceitos e contexto pessoal e social destes frente aos questionamentos propostos. $\mathrm{O}$ pesquisador deve perceber o que está além do que é dito pelo sujeito, deve ver o que está intrínseco nas respostas. Bogdan e Biklen (1999, p. 51) complementam que a metodologia qualitativa,

tem por função questionar os sujeitos da investigação [...] as suas experiências e o modo como eles próprios estruturam o mundo social que vivem [...] estabelecem estratégias e procedimentos que lhes permitem tomar em consideração as experiências do ponto de vista do informador.

Os sujeitos do estudo, sob os pseudônimos de Fridda, Capitu e Catarina, cursavam o $8^{\circ}$ semestre do curso de Letras Português/Inglês, de uma universidade do Vale do Itajaí, no estado de Santa Catarina, quando a pesquisa foi iniciada, em novembro de 2016.

Os instrumentos de investigação para entender o contexto de aprendizado e desenvolvimento acadêmico/docente das licenciandas foram: questionário semiaberto; entrevista narrativa; e, produções textuais (relatórios de estágio e relatos de experiência pessoal - texto de memórias).

O questionário foi estruturado em 23 questões, divididas em quatro aspectos: (1) perfil básico de identificação do sujeito; (2) práticas de letramentos com inglês antes do ingresso na universidade; (3) experiências de letramentos durante o curso universitário; e, (4) práticas de letramentos em inglês para a formação docente.

$\mathrm{Na}$ entrevista narrativa, as licenciandas foram convidadas a descrever suas experiências com a língua portuguesa e inglesa durante suas vidas, como se deu o contato com textos escritos e produções textuais antes e após o ingresso na universidade.

Os relatórios de estágio e os relatos de experiências pessoais (texto de memórias, em inglês), que compõem as produções textuais analisadas, foram obtidos de formas distintas. Os relatórios de estágio foram construídos ao longo da formação das acadêmicas e essa produção, ao contrário dos demais instrumentos (questionário, entrevista e texto de memórias em inglês), não foi uma proposta para atender à finalidade da pesquisa, mas, um instrumento construído a priori e utilizado a partir da autorização das estudantes. O texto de memórias foi desenvolvido para discorrer, em inglês, sobre as experiências e expectativas oportunizadas pela formação universitária, mais especificamente sobre as atividades de estágio. 
Após a aplicação dos instrumentos de investigação e a coleta dos dados, as respostas foram tabuladas e analisadas. Para a análise foram consideradas as aproximações e distanciamentos de sentidos, permitindo a construção de regularidades: (1) os letramentos em inglês antes da formação acadêmica e os motivos que levaram os sujeitos a ingressarem no curso de Letras - Português/Inglês na universidade; (2) as práticas de letramentos durante o curso universitário; e (3) as práticas de letramentos para a formação docente. Salienta-se que a escolha dos instrumentos para responder a cada um dos objetivos específicos deu-se em relação às regularidades de análise. Foi-se analisando em quais dados, advindos dos instrumentos de geração, havia proposições capazes de responder a cada regularidade e foram encontrados mais de um instrumento de dados em relação a cada objetivo específico. Os principais achados do estudo são apontados no item a seguir.

\section{Análises acerca das práticas de letramentos em inglês}

Ao serem questionadas sobre suas experiências com a língua inglesa, antes do seu ingresso na universidade, as licenciandas descreveram ter vivenciado experiências de qualificação a partir do uso da língua, levando-as ao empoderamento de seus saberes e das relações de poder colocadas a partir desse uso. Fridda diz: "Meu primeiro contato foi na escola, [...] as aulas eram em torno de vocabulário." (Questionário). "Nunca fiz curso particular." (Entrevista). Capitu afirma: "Aprendi a cantar [...] 'Mr. Wolf', na segunda série [...] gostava muito e achava fácil." (Questionário). Para Catarina: "Meu primeiro contato foi com músicas e filmes. Tenho um tio formado em Letras - inglês, que 'influenciou'." (Questionário). O empoderamento é apontado quando Capitu afirma: "Eu fiz uma viagem pra Nova Iorque, que era um intercâmbio da escola, e lá que eu tive certeza que o meu inglês era bom e que eu poderia dar aula [...] tinha chinês que falava e eu entendia".

Embora as influências para o desenvolvimento do gosto pela língua inglesa sejam distintas, as experiências com a língua também o foram, o que tornou a vivência e as práticas de letramentos significativas para cada um dos sujeitos. Essas experiências colaboraram na construção e reconstrução das identidades dos sujeitos, que inicialmente compreenderam que a habilidade com a língua as preparava para a profissão docente, parecer que foi sendo alterado com as experiências universitárias. Mas, foram os objetivos pessoais dos sujeitos que permearam a escolha do curso de graduação.

RIAEE - Revista Ibero-Americana de Estudos em Educação, Araraquara, v. 13, n. 20, p. 623-637, abr./jun., 2018. E-ISSN: 1982-5587. 
As três licenciandas concordam que as fases iniciais do curso não proporcionaram novidades em seus conhecimentos sobre a língua inglesa. Catarina aponta: "Tudo o que eu vi gramaticalmente, falando nas disciplinas de língua inglesa, são coisas simples. [...] Eu acho que a parte da teoria é fundamental! Que eu nunca havia ouvido falar." (Entrevista). Fridda diz que: "A gente começou a ver uns textos teóricos só no estágio, [...] e aí, com a vinda da nova professora [...]. A gente começou a ver textos mais novos". (Entrevista), e Capitu ressalta: "Acho que o curso não atende às expectativas em língua inglesa, a parte de língua portuguesa é tão bem explorada e o inglês parece esquecido".

Elas afirmaram que passaram a criar expectativas positivas e negativas frente aos próximos semestres, pois a qualidade de sua formação acadêmica dependia também da qualidade dos letramentos acadêmicos. As acadêmicas também consideraram deficientes os métodos de ensino empregados pelos docentes do curso para o desenvolvimento de novos docentes na língua inglesa.

Durante a realização dos seus estágios, as licenciandas analisaram a metodologia adotada pelo curso para organizar e orientar os estágios dos acadêmicos. Elas concordam que o estágio não é um processo aberto para diálogo, acordos ou discussões. Para as licenciandas, o processo do estágio se revelou estritamente burocrático e formal. Capitu afirma: "Nossa professora mal leu meu relatório de estágio, não houve observações ou comentários. [...] o estágio não era realmente para nós" (tradução nossa). (Relato pessoal - memórias). De forma geral, os sujeitos da pesquisa apontam que as práticas vivenciadas no contexto do estágio não estão de acordo com as aprendizagens e teorias sobre uma atuação profissional docente crítica, construtiva, alicerçada em práticas para a aprendizagem docente. É possível apontar para a existência de um processo de exclusão (GEE, 2001, nos termos do autor, outsider) sobre práticas de letramentos docentes na universidade em relação aos universitários.

Ao adentrarem a sala de aula na oportunidade dos estágios, as licenciandas perceberam a importância de aprimorar os métodos utilizados pela escola e pela universidade, mas preferiram não imprimir discussões, tampouco aprofundar reflexões ou críticas a estes em seus relatórios de estágio. Esses "silêncios dos sujeitos" (HEINIG, 2011, p. 244) retratam uma relação de poder implícito no discurso. Não há, portanto, uma atenção às relações de poder estabelecidas entre os saberes e expectativas dos estudantes e o que a universidade pesquisada ensina como formação em relação à língua inglesa, ou seja, não se estabelece um diálogo entre as expectativas pessoais e sociais da formação. 
Outro posicionamento comum às licenciandas foi o fato de que a prática da sala de aula observada nos estágios é diferente da teoria estudada na universidade. Catarina afirmou em sua entrevista: Não fazia ideia que existiam essas teorias de ensino, né, sobre listening, speaking, do writing, [...] sem a faculdade eu jamais aprenderia. Eu jamais me sentiria apta pra dar aula de língua inglesa sem ter conhecimento dessas teorias. No entanto, ao finalizar seu relatório de estágio Catarina acrescenta: "a prática da sala de aula mostra-se diferente da teoria estudada, pois nem sempre o ato de levar em consideração situações sociais dos estudantes e educadores, as suas realidades, objetivos e interesses pessoais acontece”. E justifica em seu relatório o porquê decidiu seguir em frente com a profissão: “ao ver os alunos interessados e aprendendo algo que antes era considerado difícil, ou muitas vezes até mesmo impossível, todo esse esforço vale a pena”.

Assim, os dados sinalizam percebe-se que apenas a teoria não sustenta a complexidade que a realidade demanda. Mas, as considerações levantadas ao final dos relatórios de estágio assinalam pareceres positivos, pois mesmo diante das adversidades da formação docente, a aprendizagem dos estudantes é um motivador para que elas sigam em frente na licenciatura. Os relatos das licenciandas revelam que a teoria apresentada na universidade é limitada e que é necessário ir além para se constituírem como docentes de língua inglesa. Mas, ao calarem-se diante da situação em seus relatórios de estágio, acabam por não contribuir para a transposição desta problemática e, tampouco para a melhora qualitativa do curso.

Assim, ao término da análise dos dados alcançados por meio das abordagens escritas e orais, é possível afirmar que no depoimento dos sujeitos desta pesquisa não ficou explicitado que esse ensinar aconteceu como um processo pensado e construído pelos letramentos acadêmicos da universidade pesquisada, tampouco foram observados nos diálogos que se estabeleceram entre os discursos das três universitárias deste estudo. Segundo Fritzen e Lucena (2012), isso é um alerta sobre a necessidade de uma abordagem metodológica de formação que foque em relações de poder, nos meios de reprodução e naturalização de práticas sociais que vão se construindo através da linguagem.

\section{Considerações finais}

A partir dos objetivos propostos para este artigo, infere-se que o inglês foi visto como perspectiva de crescimento pessoal e profissional na vida dos sujeitos, alterando a

RIAEE - Revista Ibero-Americana de Estudos em Educação, Araraquara, v. 13, n. 20, p. 623-637, abr./jun., 2018. E-ISSN: $1982-5587$. 
forma de experienciar a língua inglesa, de viver as práticas de letramentos, e orientaram a apropriação dos discursos.

As licenciandas abordaram que os conhecimentos necessários para a formação docente não estão estreitamente na teoria, mas em práticas planejadas, proporcionando ao acadêmico a construção de conhecimentos significativos a partir dos letramentos sociais necessários para atuar como docente. A constituição da identidade do futuro docente está embasada nas práticas desenvolvidas também em seus estágios, pois reconhecem que embora o estágio tenha sido burocrático e formal, que a teoria e o domínio do inglês não são suficientes para preparar o docente para lecionar, foi o estágio que oportunizou vivenciar a vontade de aprender dos estudantes, considerado pelos sujeitos da pesquisa como recompensa e determinante para abraçar a profissão.

Por meio deste estudo não é possível generalizar que os demais licenciandos do referido curso de Letras Português/Inglês da universidade pesquisada também possuem os mesmos sentimentos ou que compartilhem das mesmas opiniões. No entanto, os resultados têm o potencial de contribuir para a reflexão e tomada de decisão pelos gestores do curso, as quais simbolizam possíveis encaminhamentos futuros de pesquisa no âmbito dos letramentos acadêmicos.

AGRADECIMENTOS: Agradecemos às licenciandas pela disponibilidade e aceite em participar do estudo, tornando-o enriquecedor para a área de Letras, em especial para o contexto pesquisado. Ao colegiado do Curso por aprovar a execução desta pesquisa. E, aos professores que integraram discussões nesse processo investigativo, em torno da temática que ora se apresenta nesse artigo, da banca de qualificação e de defesa, pela oportunidade de troca de conhecimentos e experiências ao longo do processo de formação acadêmica, profissional e humana.

\section{REFERÊNCIAS}

BAKHTIN, M. Estética da criação verbal. São Paulo: Martins Fontes, 2003.

BARTON, D.; HAMILTON, M. Literacy, reification and the dynamics of social interaction. In: BARTON, D.; TUSTING, K. (Eds.). Beyond communities of practice: language, power and social context. [S. 1.]: Cambridge University Press, 2005.

BOGDAN, R.; BIKLEN, S. Investigação qualitativa em educação: uma introdução à teoria e aos métodos. Porto: Porto Editora, 1999. 
COLAÇO, S. F.; FISCHER, A. Letramentos acadêmicos em um programa de iniciação à docência: modos de interação em práticas em práticas pedagógicas. Linguagem e Ensino, Pelotas, v. 18, n. 1, p. 99-123, jan./jun. 2015.

DIONÍSIO, M. de L. Educação e os estudos atuais sobre o letramento. Revista Perspectiva, Florianópolis, v. 25, n. 1, p. 209-224, 2007.

FERREIRA, I. K. de S.; SANTOS, L. F. A aprendizagem de língua estrangeira nos anos iniciais do ensino fundamental. Letrônica, [S. 1.], v. 3, n. 1, p. 128, jul. 2010.

FISCHER, A. A construção de letramentos na esfera acadêmica. Tese (Doutorado em Linguística) - Universidade Federal de Santa Catarina, Florianópolis, 2007. 340 f.

FISCHER, A. Hidden features and overt instruction in academic literacy practices: a case study in Engineering. In: LILLIS, T. et al. (Orgs.). Working with academic literacies: case studies towards transformative practice. Parlor Press, p. 75-85, 2015.

FISTAROL, C. F. da S. Letramentos acadêmicos no curso de letras: práticas em inglês na voz de licenciandas. 2018. 126 f. Dissertação (Mestrado em Educação) - Universidade Regional De Blumenau, Blumenau, 2018. Não publicado.

FRITZEN, M. P.; LUCENA, M. I. P. (Orgs.). O olhar da etnografia em contextos educacionais: interpretando práticas da linguagem. Blumenau: Edifurb, 2012.

GEE, J. P. Reading as situated language: a sociocognitive perspective. Journal of Adolescent \& Adult literacy, Newark, v. 8, n. 44, p. 714-725, 2001.

GHIRALDELO, C. M. Representações de línguas e formação de professores. In:

CASTRO, S. T. R.; SILVA, E. R. (Org.). Formação do profissional docente: contribuições de pesquisa em LA. Taubaté: UNIATU, 2006. p. 247-261.

HAMILTON, M. Expanding the new literacy studies. In: BARTON, D.; HAMILTON, M.; IVANIC, R. (Eds.), Situated literacies: reading and writing in context. New York:

Routledge, 2000. p. 16-34.

HEINIG, O. Olhares enunciativos: reflexões sobre as pesquisas entre educação e linguagem. In: Neide de Melo Aguiar Silva; Rita Buzzi Rausch. (Org.). Pesquisa em Educação: pressupostos epistemológicos e dinâmicas de investigação. Blumenau: Edifurb, 2011, v. 1, p. 223-244.

LEA, M. R.; STREET, B. V. The academic literacies model: theory and applications. Theory into Practice, [S. 1.], v. 4, n. 45, p. 368-377, 2006.

LEFFA, V. J. (Org.). O professor de línguas estrangeiras: construindo a profissão. 2. ed. Pelotas: EDUCAT, 2008.

MARCELO, C. A identidade docente: constantes e desafios. Formação Docente, Belo Horizonte, v. 01, n. 01, p. 109-131, ago./dez. 2009. 
NÓVOA, A. (Org.). Os professores e a sua formação. Lisboa: Instituto de Inovação Educacional, 1992.

PIMENTA, S. G.; LIMA, M. S. L. Estágio e docência. 6. ed. São Paulo: Cortez, 2011.

SEIDLHOFER, B. Closing a conceptual gap: the case for a description of English as a lingua franca. International Journal of Applied Linguistics, Oslo, v. 11, n. 2, p. 133-158, 2001.

STREET, B. Eventos de letramento e práticas de letramento: teoria e prática nos novos estudos de letramento. In: MAGALHÃES, I. (Org.). Discursos e práticas de letramento: pesquisa etnográfica e formação de professores. Campinas, SP: Mercado de Letras, 2012, p. 69-92.

STREET, B. Letramentos sociais: abordagens críticas do letramento no desenvolvimento, na etnografia e na educação. Tradução Marcos Bagno. São Paulo: Parábola Editorial, 2014.

VÓVIO, C. L. Desconstruindo dicotomias: a articulação de saberes na escolarização de pessoas jovens e adultas. EJA em Debate, Florianópolis, vol. 1, n. 1. nov. 2012. Disponível em: <https://periodicos.ifsc.edu.br/index.php/EJA/article/view/873/pdf\#.V5_2SPkrIdU>. Acesso em: 1 ago. 2016.

VÓVIO, C. L.; SOUZA, A. L. S. Desafios metodológicos em pesquisas sobre letramento. In: KLEIMAN, A. B.; MATENCIO, M. de L. M. (Org.). Letramento e formação do professor: práticas discursivas, representações e construção do saber. Campinas, SP: Mercado de Letras, 2005. p. 41-64.

\section{Como referenciar este artigo}

FISTAROL, C. F. da S.; FISCHER, A.; BAILER, C. O processo de estágio na formação docente de professores de língua inglesa: um olhar de licenciandas de um curso de Letras. Revista Ibero-Americana de Estudos em Educação, Araraquara, v. 13, n. 20, p. 623637, abr./jun., 2018. E-ISSN: 1982-5587. DOI: 10.21723/riaee.v13.n2.2018.11333

Submetido em: 29/04/2018

Aprovado em: 29/05/18 